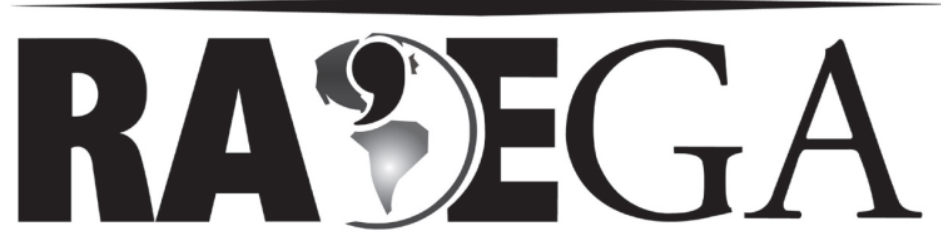

O ESPAÇO GEOGRÁFICO EM ANÁLISE

\title{
ANÁLISE IMPLICATIVA PARA AVALIAR OS ASPECTOS QUE DETERMINAM A PREFERÊNCIA POR UM BAIRRO: O CASO DE CUIABÁ, MT
}

\section{IMPLICATIVE ANALYSIS TO ASSESS ASPECTS DETERMINING RESIDENTIAL PREFERENCE: THE CASE OF CUIABÁ, MT}

\author{
Marcelo Paes de Barros ${ }^{1}$ \\ Carlo Ralph de Musis ${ }^{2}$
}

\section{RESUMO}

Este estudo buscou avaliar quais atributos de um lugar melhor explicam a imagem da residência dos moradores deste espaço a relevância dos aspectos físicos, morfologia e microclima urbanos, fornecendo subsídios para a elaboração e implantação de projetos urbanos que se adequem aos desejos da população das cidades. Para tanto foram entrevistadas 250 moradores de 5 bairros da região sudeste da cidade em paralelo a medições móveis e fixas da temperatura do ar destes espaços. Os resultados sugerem que a imagem de moradia da maior parte dos entrevistados foi mais fortemente associada aos atributos "bom investimento" e "boa localização", ficando em segundo plano as melhores condições ambientais do lugar de morada.

Palavras-chaves: Percepção ambiental; escolha residencial; clima urbano.

\footnotetext{
${ }^{1}$ Físico, Doutor em Física Ambiental pela Universidade Federal de Mato Grosso (UFMT), docente do Instituto de Física Universidade Federal de Mato Grosso (UFMT). Av. Fernando Corrêa, s/nº, bairro Coxipó, Cuiabá-MT, CEP 78060-900, tel. (65) 3615-8737, e-mail: mpb9@terra.com.br.

2 Engenheiro Civil, Doutor em Educação pela Pontifícia Universidade Católica de São Paulo, docente do Programa de Estudos Pós-Graduados em Física Ambiental da Universidade Federal de Mato Grosso (UFMT): Programa de Pós-Graduação em Física Ambiental. Instituto de Física. Av. Fernando Corrêa, s/nº, bairro Coxipó, Cuiabá-MT, CEP 78060-900, tel. (65) 3615-8000, e-mail: carlo.demusis@gmail.com
} 


\section{ABSTRACT}

This study aimed to evaluate attributes of a place that best explain the image of residence of the inhabitants of this space the importance of physical aspects, morphology and urban microclimate in the formation of this image, supporting the development and implementation of urban projects that fit the desires of the urban population. Therefore, were interviewed 250 residents of five neighborhoods in the southeast of the city parallel to fixed and mobile measurements of air temperature of these spaces. The results suggest that the image of the house most of the respondents was most strongly associated with the attributes "good investment" and "good location" in the background getting the best environmental conditions of the place of abode.

Keywords: environmental perception; residential choice, urban climate.

\section{INTRODUÇÃO}

Onde você gostaria de morar? Provavelmente a apresentação dessa questão Ihe trouxe a mente algumas imagens do seu ideário de moradia. Uma casa em uma rua arborizada, com uma boa varanda e vista para um grande lago em um parque.

Para muitas pessoas essa imagem em muito se distancia da sua realidade. Os moradores das grandes cidades do mundo, por exemplo, partilham, em intensidades diferentes, dos mesmos problemas estruturais como: trânsito congestionado, poluição sonora, falta de saneamento, inundações, poluição do ar, ambientes exageradamente aquecidos, entre outros. Essas situações cotidianas não deveriam fazer parte da imagem de residência de ninguém.

Paradoxalmente, uma suposta necessidade econômica, mantém toda uma população presa a uma situação real, distante da imagem ideal. Esta, tratada como uma utopia urbana, em algum momento de nossa trajetória foi esquecida assim como os motivos que nos trouxeram às cidades.

Algumas pessoas despertaram dessa representação compartilhada buscando refúgio em bairros distantes dos centros urbanos ou até mesmo em cidades menores, distantes das regiões metropolitanas, em busca de um ambiente mais equilibrado. No Brasil, nas últimas décadas, a desmetropolização foi o motor do crescimento populacional das cidades médias, aumentando a sua importância e originando novos processos econômicos, sociais e culturais. 
Por outro lado, ainda acreditando no sonho urbano, outros movimentos procuram reorientar as cidades, de qualquer tamanho, de forma a oferecer uma melhor qualidade de vida para sua população, baseados geralmente, em soluções coletivas, eficiência energética e reaproveitamento, onde, conscientes da finitude dos bens, aplicam a sustentabilidade.

Esse novo redirecionamento passa pela revitalização das áreas centrais das cidades, pela melhoria dos sistemas de transportes coletivos e pela busca de soluções para questões como as inundações, a poluição do ar e a formação das ilhas de calor. Algumas dessas questões estão diretamente associadas às alterações do clima das cidades que, além do desconforto térmico à população urbana, resulta em aumentos dos gastos nas áreas de energia e saúde.

Essa combinação, do clima e uso da terra, pode ter profundos efeitos sobre a habitabilidade de um espaço, mais do que qualquer agente sozinho. Neste sentido Lenzholzer e Koh (2010) julgaram que a avaliação dos efeitos do clima e do uso dos solos urbanos sobre a preferência por um lugar passa pela questão: como as percepções do microclima se relacionam com a configuração espacial de espaços urbanos ao ar livre? Segundo os autores as pessoas têm imagens ou esquemas mentais de microclimas urbanos que se relacionam com a disposição espacial do lugar. Os esquemas, baseados em processos de aprendizagem, são desenvolvidos pelas pessoas em uma infinidade de circunstâncias, sobre a interpretação de muitos estímulos diferentes. No caso da percepção ambiental estes estímulos podem ser determinadas situações, configurações espaciais, ou elementos morfólogicos, funcionando como pistas ambientais para entender se o clima de um lugar define, ou ao menos influencia a preferência por um ambiente.

O esquema mental de residência de um indivíduo, o espaço de nossa felicidade, segundo Bachelard (1993), são imagens apreendidas ao longo da história de vida da pessoa, com laços construídos a partir da história de interação com o lugar. Para Tuan (1980) esses laços se constituem em uma afeição pelo lugar, denominada por topofilia, que variando muito em amplitude emocional e intensidade, assumem muitas formas: uma evocação de orgulho de posse ou de criação; um apego por ser familiar e 
representar o passado; uma alegria nas coisas devido à saúde e vitalidade animal; um prazer visual efêmero ou um deleite sensual de um contato físico.

Addison (2003), em estudo sobre a percepção dos moradores de Florianópolis, Santa Catarina, em relação à cidade encontrou como elementos perceptivos mais importantes referenciados pela população a qualidade de vida, as belezas naturais, as praias e o bucolismo dos bairros. A autora também relatou que mesmo com os problemas ambientais resultantes das transformações ocorridas na llha de Santa Catarina, os moradores da ilha apresentaram um grau mais acentuado de topofilia em relação aos moradores do continente, de forma que o encantamento e a sedução da cidade, principalmente da parte insular, recompensam seus habitantes pelos problemas que enfrentam. Neste sentido, Tuan (1980, p.67) destacou que os indícios de alteração da paisagem local ganham extrema importância, "uma vez que representam mais que novas configurações físicas, mas a perda de referenciais sócio-históricos, substratos onde se ancora o universo de significações atribuído ao lugar".

Llinaresa e Pageb (2008) em estudo realizado em Valência, Espanha, utilizaram uma ferramenta denominada Engenharia Kansei para avaliar as respostas dos sujeitos para os atributos mais importantes para a escolha de uma área particular para viver. Neste trabalho, usando 250 diferentes adjetivos sobre ambientes residenciais que descrevem um bairro, citados por 159 entrevistados, os atributos mais importantes, que explicam a maior parte das percepções, estiveram relacionados com a paz, a amizade entre os vizinhos e a calma de um bairro.

A vizinhança agradável e as amizades podem fazer parte de um mesmo eixo temático dentro do espaço semântico de elementos perceptivos. A possibilidade de agrupar diferentes elementos perceptivos em um mesmo eixo temático para levantar os atributos que definem a preferência de um indivíduo por um ambiente são características que tornam a estatística multivariada adequada ao objetivo pretendido. A análise hierárquica coesitiva e implicativa, como todos os métodos de análise estatística de dados multidimensionais, segundo Gras e Almouloud (2002), fornece uma ferramenta prestante a visualizar, organizar, construir modelos e explicar fenômenos associados aos dados, evidenciando o comportamento ou as imagens mentais de sujeitos em diferentes situações. 
Barros et al. (2010) utilizaram o aplicativo Classification Hiérarchique Implicative et Cohésitive (CHIC) para realizar uma análise coesitiva e implicativa com o objetivo de observar as coesões entre as diferentes percepções dos visitantes de um parque urbano da cidade de Cuiabá, MT, em relação a este ambiente. Este estudo mostrou que a qualidade estética da vegetação e a qualidade ambiental, especificamente a acústica, ausência de sons urbanos, e térmica, comprovada por um estudo microclimático realizado em paralelo, entre outros fatores, foram os aspectos perceptivos mais citados pelos usuários do espaço. O aplicativo $\mathrm{CHIC}$, por meio da análise implicativa clássica com base na lei binomial, favoreceu a compreensão das relações e coesões, e as intensidades relativas destas, entre os termos evocados em entrevistas, permitindo inferir possíveis caminhos explicativos para o tema em estudo.

Nesta forma de análise mesmo elementos perceptivos opostos como rural e urbano, quente e frio ou sombra e sol, ocupam o mesmo eixo temático definindo a importância do aspecto, seja positivo ou negativo. Segundo Tuan (1980) a mente humana além de segmentar e classificar os contínuos da natureza tem a tendência de arranjar os seus fragmentos em pares opostos e atribuir significados também opostos a cada elemento do par.

A dicotomia entre os ambientes rural e urbano, por exemplo, tem sido um assunto intrigante de estudo para pesquisadores de diversas áreas em diferentes países. Alguns destes estudos buscam respostas para as diferenças de saúde entre populações de áreas urbanas e rurais. Em um estudo epidemiológico na Holanda, realizado através de entrevistas com grupos controlados por idade, sexo e padrão sócio-econômico, Maas et al. (2006) sugeriram que a disponibilidade de áreas verdes, dentro de um raio de $1 \mathrm{~km}$ a $3 \mathrm{~km}$ do ambiente residencial, foi associada pelas pessoas como um ambiente saudável. Os autores explicaram que essa percepção, associada as diversas funções da vegetação no ambiente urbano, entre elas a amenização climática, podem influenciar as preferências e as atitudes das pessoas, refletindo em um estilo de vida mais saudável.

Para Monteiro (2003) a percepção humana do clima das cidades acontece em canais que apresentam entre eles uma íntima vinculação, sendo a percepção do conforto térmico o canal que aglutina os elementos climáticos e suas produções em 
conjuntos. Mendonça (2003) sugeriu que, para o canal de percepção do conforto térmico, a ilha de calor representa o fenômeno mais significativo do clima urbano e sua intensidade depende das condições micro e mesoclimáticas locais da cidade.

Para Sartori (2000, p.57) a apreensão dos elementos perceptivos que formam a imagem de residência de um indivíduo passa também pelos efeitos psicológicos resultantes de processos fisiológicos humanos provocados pelo clima e pelas ações humanas, aplicadas aos vestuários e construções, voltadas para modificar o estresse provocado pelo próprio clima. De acordo com Lenzholzer e Koh (2010) este aprendizado faz com que as pessoas adquiram uma percepção climática, de forma a ser possível estabelecer relações entre configurações espaciais com as propriedades mais prováveis dos correspondentes microclimas. A percepção climática a partir das configurações espaciais de um ambiente pode ser responsável pela influência da morfologia urbana na escolha do local de moradia.

Nesse contexto, a escolha do ambiente residencial por um indivíduo deve ser analisada a partir de perspectivas diferentes. Muito mais que apenas uma questão econômica, perspectivas psicológicas, fisiológicas e físicas também influenciam esta decisão, porém a complexidade inerente ao tema torna impossível o julgamento de relevância de um aspecto sobre os outros. Fruto da composição destas perspectivas, a imagem de residência é ponderada pelas necessidades situacionais do indivíduo. Entendendo desta forma, e considerando que as demais perspectivas fogem do escopo deste trabalho, o artigo apresenta o resultado de um estudo que procurou avaliar que aspectos de um imóvel são responsáveis pela formação da imagem de residência de uma população, além de investigar a relevância dos aspectos físicos, morfologia e microclima urbanos, e a consequente qualidade ambiental, na formação dessa imagem.

Assim, compreendendo como os diferentes aspectos influenciam na escolha do ambiente residencial será possível sugerir diretrizes de desenho urbano que resgatem as melhores condições de vida, esquecidas como as razões que, na origem, nos fizeram morar nas cidades. 


\section{METODOLOGIA}

\section{1 Área de Estudo}

\subsubsection{Características Gerais}

Fundada em 8 de abril de 1719 por bandeirantes paulistas que, paralelamente à extração de ouro, buscavam índios neste sertão brasileiro, Cuiabá, a Capital do estado de Mato Grosso, situada à margem esquerda do rio de mesmo nome, nasceu de um arraial onde foram construídas casas, igrejas e estabelecido um pequeno comércio com a necessidade de regularizar o abastecimento para seus habitantes, ocupados somente com a mineração (SIQUEIRA, 2000).

A decadência das minas auríferas no final do século XVIII, a Guerra do Paraguai (1865 - 1870) e um mal trazido pelos combatentes, ainda pior que a própria guerra, a varíola, refletiram diretamente sobre a vida da cidade. Isolada do restante do País, o seu abastecimento passou a ser realizado pelas grandes propriedades de senhores de escravos e pequenos sítios dedicados a gêneros de abastecimento ao mercado local.

Ao final do século XIX e início do século XX desenvolveu-se no estado o ciclo econômico da exploração vegetal, em especial da erva-mate, poaia e borracha. "Na primeira metade do século $\mathrm{XX}$, o redirecionamento da política econômica do país atribuiu ao estado um novo papel", absorver mão-de-obra excedente de outras regiões e se transformar em produtor de alimentos (HIGA, 2005, p.32).

A intensificação deste processo produziu, na década de 1980, as mais altas taxas de crescimento populacional da história da cidade, com uma expansão de $136 \%$ do seu sítio urbano sobre as áreas periféricas. O ritmo de crescimento da cidade não foi acompanhado pelo investimento do setor público em infraestrutura e serviços para atender as necessidades da população. A demora no atendimento dessas necessidades resultou na ocupação ilegal de áreas periféricas, originando os bairros Santa Izabel, Del Rei, Renascer, entre outros (VILARINHO NETO, 2005). O crescimento desordenado da área urbana gerou grandes problemas ambientais como: córregos assoreados e cheios de esgoto, poluição do ar e sonora e a formação de ilhas de calor nas áreas centrais (PIAIA, 1997).

Atualmente a Região Metropolitana do Vale do Rio Cuiabá (RMVRC), estabelecida pela Lei Estadual Complementar 27/2009, compreendendo os municípios 
de Cuiabá, Várzea Grande, Nossa Senhora do Livramento e Santo Antônio de Leverger, apresenta uma população de 834.060 habitantes, com tendência de crescimento (IBGE, 2010). Atendendo aos municípios do estado e de estados vizinhos em diferentes áreas socioeconômicas, especialmente no setor de serviços, os municípios da RMVRC consolidam a função de metrópole regional com o desafio de transformar estes espaços em ambientes mais saudáveis e produtivos.

\subsubsection{Características Climáticas}

Localizada na porção central da América do Sul, nas coordenadas geográficas $15^{\circ} 35^{\prime} 56^{\prime \prime}$ latitude Sul e 56 06' 01" longitude Oeste, na zona intertropical do Planeta, a RMVRC tem seu clima identificado prioritariamente pela temperatura. Segundo a classificação de Köppen, o clima da região é do tipo Aw, típico do regime tropical de savana com duas estações bem definidas, uma seca, que se prolonga de abril/maio a setembro/outubro, e outra chuvosa. As temperaturas médias anuais oscilam entre $25^{\circ} \mathrm{C}$ e $26^{\circ} \mathrm{C}$, enquanto as máximas ultrapassam, frequentemente, $35^{\circ} \mathrm{C}$ durante quase o ano todo (MAITELLI, 2005).

Campelo Júnior et al. (1991, p.548), utilizando dados do Instituto Nacional de Meteorologia (INMET) do período de 1970 a 1989, registrou a ocorrência de 54 dias por ano, em média, no período de 21 de agosto a 07 de abril com temperaturas médias superiores a $28^{\circ} \mathrm{C}$, "sendo mais frequente que estes ocorram isoladamente, embora exista a possibilidade de ocorrerem em períodos contínuos de até 16 dias". Com relação às temperaturas mínimas, em média, ocorrem 17 dias por ano com temperatura média inferior a $20^{\circ} \mathrm{C}$, frequentemente de ocorrência isolada, sendo possível que ocorram períodos contínuos de até 10 dias abaixo de $20^{\circ} \mathrm{C}$.

A ocorrência de períodos de curta duração com temperatura baixa alternando-se a temperaturas moderadas ou elevadas durante o período do inverno é uma característica marcante do clima na RMVRC. As temperaturas baixas ocorrem em conseqüência da invasão de Massa Polar do Atlântico, enquanto que as altas da primavera e verão podem ser atribuídas à ação da Massa Tropical Continental (CAMPELO JÚNIOR et al., 1991).

A umidade relativa do ar varia muito conforme os períodos de seca e chuva. No período de seca em algumas localidades da região são registrados índices de umidade 
relativa do ar inferiores a $30 \%$ entre os horários de 10 h e 16 h (GUARIM \& VILANOVA, 2008). Na região predominam depressões e planícies com altitudes entre 95 m e 200 $\mathrm{m}$. Apresentando valores totais anuais de precipitação menores que no restante do estado, por volta de $1200 \mathrm{~mm}$ a $1500 \mathrm{~mm}$, a região ainda apresenta os maiores valores de perdas superficiais por evapotranspiração, aproximadamente entre 1340 mm e 1450 mm (MAITELLI, 2005).

A direção do vento é predominantemente $\mathrm{N}$ e NO na maior parte do ano e $\mathrm{S}$ no inverno. Apesar da baixa velocidade média do vento ao longo do ano, picos de velocidade acontecem em períodos de curta duração.

\subsubsection{Apresentação dos Bairros do Estudo}

Para a realização deste trabalho, em virtude da metodologia utilizada para a análise microclimática, o método do transecto móvel, foram escolhidos apenas 5 bairros da região sudeste da cidade, onde o processo de urbanização se apresentou mais intenso nos últimos 30 anos. A escolha dos bairros foi baseada nos aspectos da proximidade entre suas áreas, da concentração de áreas construídas e áreas verdes, do adensamento populacional, da complexidade do uso do solo e da heterogeneidade, quanto à situação social, dos moradores destes espaços (Figura 01).

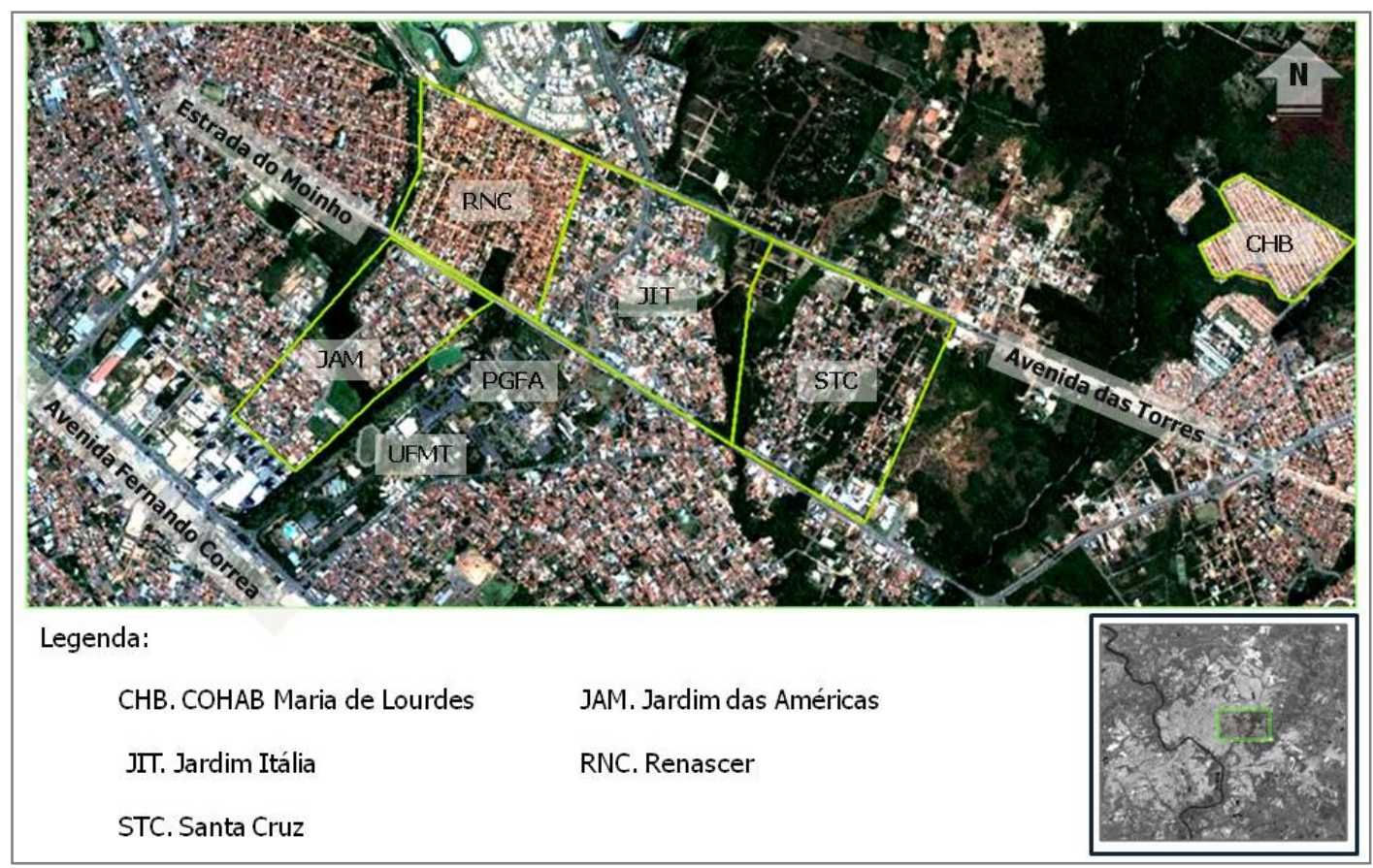

Figura 01 - Área de estudo.

Fonte: Google Earth, 2010; INPE, 2009. 
O loteamento Jardim das Américas, constituído nas vizinhanças da av. Fernando Corrêa da Costa e da Universidade Federal de Mato Grosso (UFMT), cuja implantação da primeira etapa durante a década de 1980 ocupou parte do antigo leito do córrego do Barbado, que foi desviado e retificado. A segunda etapa do bairro Jardim das Américas foi construída sobre uma várzea localizada entre dois braços do mesmo córrego. Da área aterrada sobreviveram dois pequenos trechos brejosos, um deles cortado pela Estrada do Moinho, entre os bairros Renascer e o Pedregal, e o outro margeando o córrego ao lado do Jardim das Américas (GALDINO \& ANDRADE, 2008).

Na década de 1990, uma galeria de lojas denominada Três Américas, ocupando a porção desviada do córrego do Barbado, expandiu as atividades sendo elevada a categoria de shopping. O Shopping Três Américas atraiu uma série de serviços para suas vizinhanças constituindo na região um dos centros comerciais mais movimentados da capital mato-grossense. Atualmente o Jardim das Américas é um bairro comercial, empresarial e residencial, com construções verticais e horizontais, apresentando, em termos de valores, um dos espaços mais caros da cidade.

A segunda onda de expansão da região, na década de 1990, provocada pela consolidação do Shopping Três Américas, deu origem a formação de alguns bairros na porção posterior da UFMT, entre estes os bairros Jardim Itália (JIT) e Santa Cruz (STC), loteamentos planejados pela mesma incorporadora.

$\mathrm{Na}$ atualidade estes bairros apresentam características diferentes quanto a ocupação dos solos. Enquanto o Jardim Itália é um bairro consolidado, com quase a totalidade dos lotes construídos, no Santa Cruz muitos dos lotes ainda não foram ocupados, mantendo ainda extensos fragmentos do cerrado original da região. Com parte das ruas ainda não asfaltadas e ausência de áreas de lazer, o bairro Santa Cruz, mais lembrado pelo hospital que existia no lugar, ainda espera pela infraestrutura. No Jardim Itália também não existem praças e a única área verde se encontra na divisa deste bairro com o Santa Cruz, a nascente de um córrego que divide os bairros é uma área de preservação permanente (APP).

Em 1997, o bairro Jardim Itália, teve parte de seu território invadido formando o que viria a ser o bairro Renascer (RNC). No ano 2000, com o apoio do Governador do 
Estado, Dante de Oliveira, a área foi doada às famílias que estavam assentadas no local. Esta ação discutível foi uma das poucas relações do poder público com o Renascer. A inexistência de escolas, creche, polícia comunitária, espaços para lazer e saneamento básico deixa evidente a falta de políticas públicas dirigidas ao bairro.

Em 2009 uma terceira onda de expansão motivada pela construção da avenida Edna Affi, a Avenida das Torres, deu origem a muitos loteamentos de iniciativa privada e outros conjuntos habitacionais populares financiados pelo poder público, como os Residenciais Recanto do Salvador, Despraiado e Maria de Lourdes.

O Conjunto Habitacional Maria de Lourdes (CHB) entregue em junho de 2006 é resultado do Programa de Arrendamento Residencial (PAR) do Ministério das Cidades, e executado pela Caixa Econômica Federal (CEF) em parceria com o Governo do Estado de Mato Grosso, dirigido a atender as necessidades de moradia da população de baixa renda, especificamente aquelas famílias que recebem até 6 salários mínimos mensais.

O Conjunto Habitacional Maria de Lourdes apresenta todas as ruas asfaltadas e as calçadas arborizadas com espécies da região. As áreas de lazer do lugar se encontram abandonadas, ocupadas por uma vegetação rala, e as áreas verdes, inexistentes no interior do bairro, são abundantes no seu entorno, todas pertencentes a sítios do cinturão verde da capital.

Os cinco bairros delimitados para o estudo ocupam uma área total de $8,0 \mathrm{~km}^{2}$, separados, de um extremo a outro, por uma extensão linear de $5,0 \mathrm{~km}$, posicionados nas adjacências das vias estruturantes paralelas, av. Fernando Correa da Costa, av. das Torres e Estrada do Moinho, todas com acesso à BR 364, principal ligação da cidade com a região sul do País.

Assim foi constituída a área delimitada para este estudo. Um espaço heterogêneo com fortes contradições sociais. Bairros de população de alto poder aquisitivo, bairros populares e assentamentos irregulares estão presentes ao longo de toda área, acomodando habitações de alto padrão, verticais e horizontais, condomínios fechados, shopping center, em lugares com infraestrutura de água, energia, linha de ônibus, pavimentação asfáltica, e outros sem pavimentação e abastecimento de água e saneamento precários. 


\subsection{Avaliação da Preferência Ambiental}

Procurando um melhor entendimento da questão da preferência de um determinado local para habitação em detrimento de outros foram realizadas entrevistas semiestruturadas para avaliar quais os elementos perceptivos mais influenciam na escolha do ambiente residencial desta amostra da população da cidade de Cuiabá.

A aplicação do instrumento de coleta de dados foi realizada durante o mês de agosto de 2011, de forma individual, apenas com os moradores dos bairros. Todas as impressões e informações coletadas foram registradas pelos pesquisadores nos instrumentos aplicados.

Os resultados desta avaliação forneceram indícios da importância da qualidade ambiental na escolha do ambiente residencial por esta população. No âmbito do planejamento urbano, a qualidade ambiental deve ser entendida como ausência de poluição, lixo e ruídos, e uma arborização e morfologia urbana que confiram as melhores condições microclimáticas possíveis para aquele clima local.

Um estudo prévio, de acordo com o roteiro metodológico proposto por Llinaresa e Pageb (2008), foi realizado para a obtenção do instrumento de pesquisa. Para tanto buscou-se palavras e expressões, principalmente adjetivos, usados pelas pessoas para expressar os atributos de um imóvel para moradia. Utilizando como fontes a internet, jornais e revistas profissionais, foram relacionadas mais de uma centena de expressões como: excelente localização, espaço ideal, melhor vista, seus melhores momentos, rua tranquila e arborizada, áreas de lazer e muito verde, clima agradável, entre outros.

Essa técnica reduziu o número de palavras ao formar grupos de palavras escolhendo aquelas mais gerais para representar os grupos. As expressões escolhidas, o espaço semântico, foram classificadas em oito eixos que refletiram aspectos relacionados com o esquema mental de residência de um indivíduo:

- Eixo 1. Grupo com referências como "abundância de vida noturna e despreocupada", "jovem", "vital", "alegre", "animado", "dinâmico" e "com serviços de lazer e entretenimento". Apresenta uma correlação negativa com adjetivos tais como condições de tráfego "intenso", "pesado" e "barulhento", interpretado como a dimensão do tráfego e do ruído; 
- Eixo 2. Ele contém as variáveis relacionadas com o conceito de fácil acesso e rápido, tais como "boas ligações", "boas ligações de transportes públicos", "bem situados", "fácil chegar ao local de trabalho" e "bom planejamento urbano";

- Eixo 3. Corresponde conceitualmente à prospectiva de um bom investimento com a "expansão", "desenvolvimento urbano", com perspectivas promissoras de futuro como conceitos principais;

- Eixo 4. Este eixo inclui os descritores "com parques e áreas de lazer", "ampla área, grandes espaços abertos", "boas instalações desportivas", "clima agradável" e "bem arborizado", além dos termos espaçosos e paisagísticos. Este eixo pode ser interpretado como o eixo do conforto ambiental;

- Eixo 5. Este eixo pode ser interpretado como o eixo de luxo e prestígio. Apresenta uma forte correlação positiva com expressões como "de luxo", "requintado", "alta classe", "prestígio", "sem problemas de segurança", "elegante, moderno" e uma correlação negativa com expressões tais como "imigrantes", "marginal", "multicultural" e "deteriorando";

- Eixo 6. Este eixo está relacionado com os adjetivos "comercial", "com boas lojas" e "área de negócio". Ele representa o eixo comercial e empresarial;

- Eixo 7. Representa a dimensão emblemática e caráter distinto de um imóvel sendo composto por expressões como "emblemático", "único e especial", "num ambiente histórico" e "com personalidade e caráter próprio";

- Eixo 8. Pode ser entendido por expressões como "pacífica", "amigável" e "vizinhança agradável", com uma grande variedade de escolas.

Assim constituídos, cada eixo recebeu um título e foram relacionados em ordem alfabética para compor o instrumento definitivo, apresentado no Anexo I, base das entrevistas.

Aplicado inicialmente a uma população de 250 pessoas distribuídas igualmente nos 5 bairros, o instrumento de pesquisa abordou os itens:

a. A afeição pelo lugar de moradia;

b. Os elementos perceptivos, positivos ou negativos, do lugar de moradia;

c. A percepção da qualidade ambiental do lugar que vive; 
d. A sua participação nesta qualidade.

Para avaliar os aspectos perceptivos mais importantes para a preferência residencial de um indivíduo foi solicitado aos entrevistados que apontassem, de forma objetiva, quais dos eixos julgavam mais relevantes para uma possível escolha de um ambiente residencial.

O roteiro da coleta de dados também apresentou uma questão aberta baseada em evocações livres que procurou avaliar a imagem do lugar onde reside o entrevistado, além de outras 3 questões objetivas avaliando a qualidade ambiental do seu bairro, especificamente quanto ao conforto térmico, sua relação com a arborização e a contribuição efetiva de cada um para a constituição do clima urbano. Correspondendo a estímulos projetivos de caráter espontâneo, as evocações livres permitiram acessar, de forma menos controlada, "os elementos que constituem o universo semântico do termo ou do objeto estudado." (ABRIC, 1994, p.66).

Para essa questão aberta foi orientado aos entrevistadores que gravassem, ou anotassem, todos os argumentos a respeito do ambiente de moradia do indivíduo, para posterior transcrição ipsis litteris e embasamento de possíveis discussões a respeito das preferências apontadas pelos eixos temáticos.

A base de dados obtida serviu de referência para a avaliação da saturação da coleta de informações, procedimento utilizado para inferir sobre a suficiência do volume de dados coletados para a população em estudo, de acordo com o roteiro metodológico proposto por De Musis et al. (2009) para avaliação da saturação de questões abertas. A saturação pode ser qualitativamente definida como o "tamanho de amostra em que a inclusão de novos participantes apresenta uma redundância tal que, conforme critério definido pelo pesquisador, pouco acrescenta ao material já obtido" (DE MUSIS et al., 2009, p.506).

A avaliação da saturação da coleta de dados foi realizada por um procedimento de simulação Monte Carlo, variando os indivíduos selecionados e o tamanho da amostra com o auxílio do aplicativo Crystal Ball, da Oracle.

Posteriormente foi realizada uma análise exploratória dos dados por estatística coesitiva, na qual as expressões que compuseram o espaço semântico de 
qualificações dos bairros foram processadas pelo aplicativo $\mathrm{CHIC}$, que por meio da análise implicativa clássica auxiliou na compreensão das relações entre os eixos temáticos, permitindo inferir possíveis caminhos discursivos entre eles. Como resultado o software apresentou uma árvore de similaridades, um gráfico implicativo de possíveis coesões entre as respostas dos entrevistados sobre aspectos das variáveis levantadas no início do estudo.

O resultado dessa análise forneceu subsídios necessários para avaliar os aspectos de percepção, topofilia e imagem de residência dos moradores desta região da cidade.

\subsection{Medições Microclimáticas}

Para embasar as discussões, com respeito as preferências ambientais e os respectivos ambientes térmicos, foi realizada uma análise microclimática do ambiente de estudo. $\mathrm{O}$ ambiente térmico de cada microclima dos bairros foi caracterizado pelo método de medições móveis. Este método e sua instrumentação utilizados neste trabalho foram adaptados com base nos trabalhos realizados por Kaiser e Faria (2001), aplicado em Bauru, SP, e Pezzuto (2007), em Campinas, SP.

A implementação do método contou com a instalação do conjunto de medidores, termômetro digital portátil com data-logger e sensor de par termoelétrico tipo $\mathrm{K}$, na lateral do veículo para realização das medições móveis. Para a localização automática dos pontos percorridos pelo veículo foi utilizado um GPS que, sincronizado com o registrador da temperatura do ar, programado para registrar e armazenar dados a cada 10 segundos, garantiu que todo ponto com registro de temperatura do ar fosse devidamente georreferenciado.

Para a correção do tempo tardio foram instalados 5 registradores da temperatura do ar com data-logger locados na porção central dos bairros, as medições fixas. Estes registros foram utilizados para corrigir para os horários padrões das medições as medidas móveis de cada bairro, a partir da evolução da temperatura do ar na porção central do mesmo.

Com exceção do horário das $02 \mathrm{~h}$, as medições móveis aconteceram nos horários padrões recomendados pela Organização Mundial de Meteorologia (WMO) 
para as principais observações meteorológicas de um dia típico, às $00 \mathrm{~h}, 06 \mathrm{~h}, 12 \mathrm{~h} \mathrm{e}$ 18 h GMT (Greenwich Meridian Time), correspondentes às 20 h, 02 h, 08 h e 14 h, horário local. As medições tinham início, aproximadamente, trinta minutos antes do horário padrão e, dependendo das condições locais de trânsito, eram completadas após uma hora e 15 minutos.

As medições aconteceram em quatro períodos ao longo de um ano, dois em cada estação, em datas definidas pela disponibilidade da equipe de medições e pela previsão de três dias, no mínimo, de condições meteorológicas estáveis, de céu claro, sem chuva e com ventos reduzidos. A Tabela 01 apresenta os dias de medições para coleta de dados.

Tabela 01 - Períodos de medições

\begin{tabular}{cc}
\hline Estação & Período de Coleta \\
\hline Seca & 06 a 10 de setembro de 2010 \\
Chuva & 13 a 17 de dezembro de 2010 \\
Chuva & 18 a 22 de abril de 2011 \\
Seca & 08 a 12 de agosto de 2011 \\
\hline
\end{tabular}

\section{RESULTADOS E DISCUSSÃO}

\subsection{Análise Microclimática}

Para esta análise foram utilizadas as temperaturas médias de cada bairro, ao longo dos transectos de cada horário padrão e estação (Figura 02).

As menores temperaturas médias em quase todos os horários das duas estações foram encontradas no bairro STC, justificada pela presença de áreas verdes em quantidade e complexidade. Confirmando essa tendência, os bairros JIT, JAM e $\mathrm{RNC}$, com índice de áreas verdes em quantidades muito semelhantes apresentaram ambientes térmicos semelhantes nas duas estações do ano. 


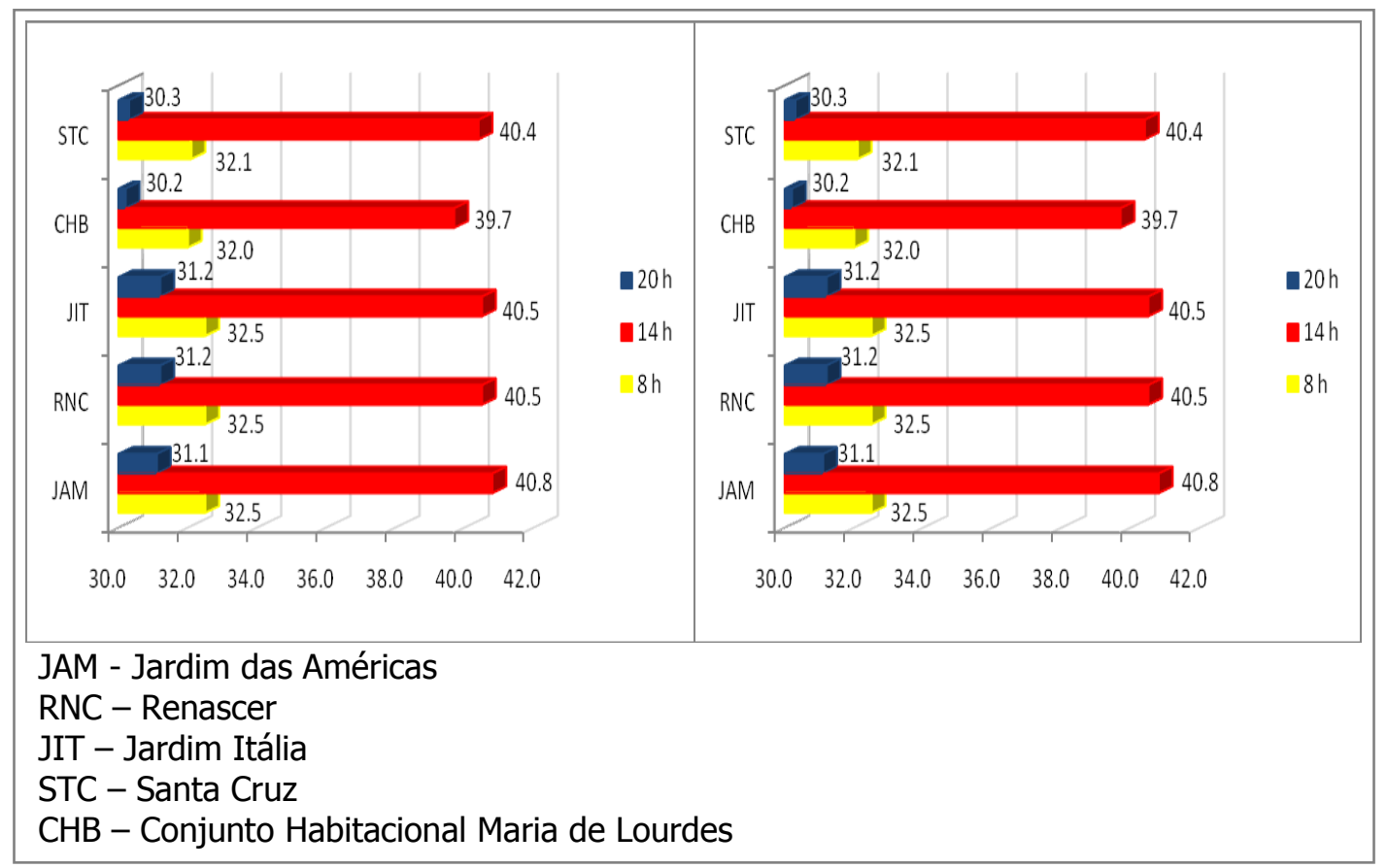

Figura 02 - Temperatura média do ar por bairro para o período de medições.

No $\mathrm{CHB}$ os resultados confirmaram o padrão de construções térreas, caracterizadas pelas elevadas densidade de construções e impermeabilização dos solos e reduzidas arborização pública e áreas verdes, como determinantes para as maiores temperaturas apresentadas no período vespertino neste bairro. No entanto, no período noturno das duas estações do ano ocorrem fortes atenuações da temperatura do ar justificadas pela mata que envolve o bairro.

Segundo as medições fixas, a maior amplitude térmica fol registrada no medidor colocado no JAM, de $15,0^{\circ} \mathrm{C}$ na estação seca,. As menores temperaturas aconteceram no STC, de $23,5{ }^{\circ} \mathrm{C}$ na estação seca e de $23,2^{\circ} \mathrm{C}$, na estação chuvosa. As maiores temperaturas registradas nos dias de medições foram de $42,4{ }^{\circ} \mathrm{C}$ no $\mathrm{CHB}$ na estação seca e de $37,6^{\circ} \mathrm{C}$ no JAM na estação chuvosa. Nesse último, apesar da proximidade à vegetação do córrego do Barbado, os possíveis efeitos de arrefecimento da temperatura do ar foram anulados pelas características do lugar, de elevada taxa de impermeabilização dos solos e adensamento das construções.

A forte influência de uma região com um percentual elevado de fragmentos arbóreos pôde ser percebida nos bairros Jardim Itália e Santa Cruz. No Jardim Itália, 
com características próximas ao Renascer e ao Jardim das Américas Horizontal, a presença de um grande fragmento arbóreo fez com que a temperatura média deste bairro fosse, em todos os horários, inferior às registradas nos bairros com padrões espaciais semelhantes. No Santa Cruz, o elevado percentual de áreas verdes, bem distribuído por todo o bairro, resultou em um ambiente térmico, em média, com menores registros que os demais bairros em todos os períodos das duas estações, além do registro da menor temperatura do ar para o estudo às $6 \mathrm{~h}$ da estação seca.

\subsection{Avaliação do Grau de Saturação do Padrão de Respostas}

Para o estudo dos aspectos físicos que constituem a imagem de residência dos moradores dos bairros do estudo foram entrevistados, inicialmente, 50 indivíduos por bairro, totalizando 250 indivíduos, que forneceram um total de 25 evocações diferentes. A técnica de amostragem foi probabilística, de forma que cada bairro foi dividido em cinco regiões onde, em cada uma destas, foram realizadas 10 entrevistas.

A amostra inicial de 250 indivíduos foi submetida a quatrocentas reamostragens pelo método de simulação Monte Carlo, com número de sujeitos variando de um a 250 , de forma a estimar uma referência prática para a saturação da coleta de dados. A Figura 03 apresenta o modelo obtido com melhor ajuste, uma curva de saturação crescente até o ponto de máximo que, conforme uma interpretação visual, começa a partir de 100 indivíduos. 


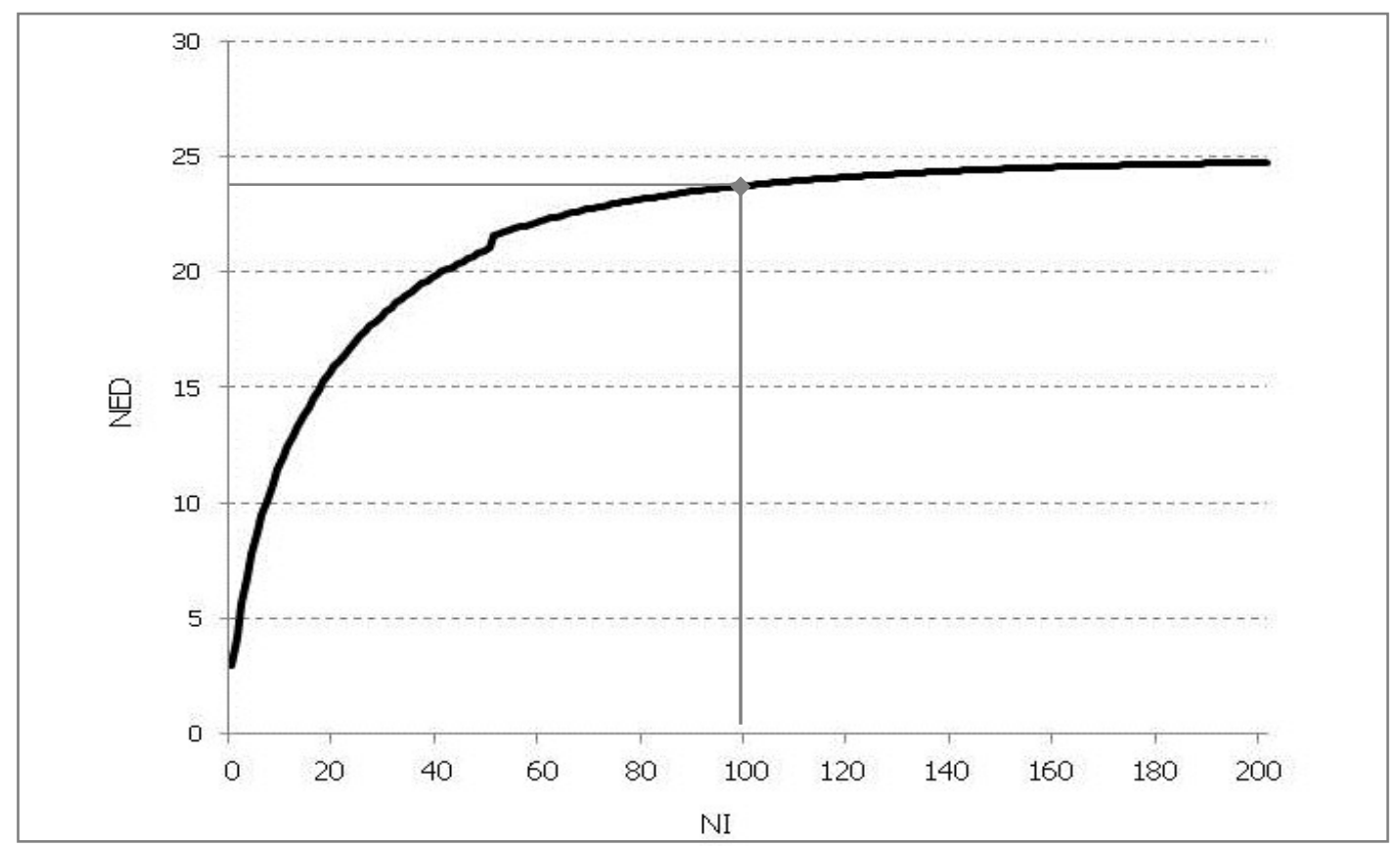

Figura 03 - Gráfico de regressão entre o Número de Indivíduos (NI) e o Número de Evocações Diferentes (NED).

Assim, o procedimento para avaliar a saturação do padrão de respostas à questão aberta indicou a suficiência da base de dados para a análise, uma vez que o ponto de referência prático para a saturação foi menor que a amostra de base utilizada.

Estabelecido o banco de dados, as análises das entrevistas, além de permitirem identificar o perfil dos moradores de cada bairro, foram suficientes para permitir inferências sobre o comportamento da população nos quesitos relacionados no instrumento de pesquisa. Os resultados possibilitaram uma melhor compreensão dos fenômenos perceptivos estudados e conciliados com os objetivos proposto, estabelecendo que elementos perceptivos, entre eles o clima e a arborização do lugar, foram mais decisivos na escolha de um indivíduo por um lugar de moradia.

\subsection{Análise dos Aspectos Que Constituem a Imagem de Residência da População dos Bairros}

Para esta análise os entrevistados foram separados por sexo e classificados em três faixas etárias, de 15 a 25 anos, 26 a 49 anos e acima de 50 anos, uma vez que a 
percepção de um ambiente varia significativamente entre homens e mulheres e entre indivíduos com idades diferentes.

Caracterizada a população dos moradores dos bairros, procurou-se estabelecer as diferentes imagens e percepções do espaço, de um modo geral, para os seus moradores. Para melhor caracterizar os resultados quanto às representações mentais de cada lugar e do ideário de moradia, as respostas dos entrevistados no quesito adjetivos mais importantes para aquisição de uma residência e as razões para tanto, foram classificadas em 8 eixos temáticos, apresentados na Tabela 02 e constituídos conforme apresentado no item 2.2 deste artigo, onde foi descrita a metodologia da pesquisa.

Tabela 02 - Eixos Temáticos em que foram classificadas as respostas dos entrevistados

\begin{tabular}{lc}
\multicolumn{1}{c}{ Eixos Temáticos } & Respostas Mais Comuns \\
\hline E. $_{1}$ ANIMADO E DINÂMICO & Vida noturna e serviços de lazer \\
E. $_{2}$ BOA LOCALIZAÇÃO & Fácil acesso e bem situado \\
E. $_{3}$ BOM INVESTIMENTO & Expansão promissora e perspectiva de futuro \\
E. $_{\text {. CLIMA AGRADÁVEL }}$ & Áreas de lazer e muito verde \\
E. $_{5}$ ELEGANTE E MODERNO & Prestígio e requinte \\
E. $_{6}$ EMPRESARIAL E COMERCIAL & Boas lojas e área de negócios \\
E. ÚNICO E ESPECIAL $_{\text {E. VIZINHANÇA AGRADÁVEL }}$ & Essencial e sem igual \\
\hline
\end{tabular}

As respostas de cada individuo, classificadas segundo os eixos temáticos, foram submetidas ao aplicativo CHIC v.3.1 para a análise de similaridade entre as respostas de cada entrevistado. A aplicação de um procedimento de classificação às categorias das respostas de cada usuário, usando o método entrópico e a distribuição binomial, produziu a árvore de similaridades de poucas classes com quatro elementos em cada classe, conforme Figura 04. 
$\mathrm{A}_{1}$

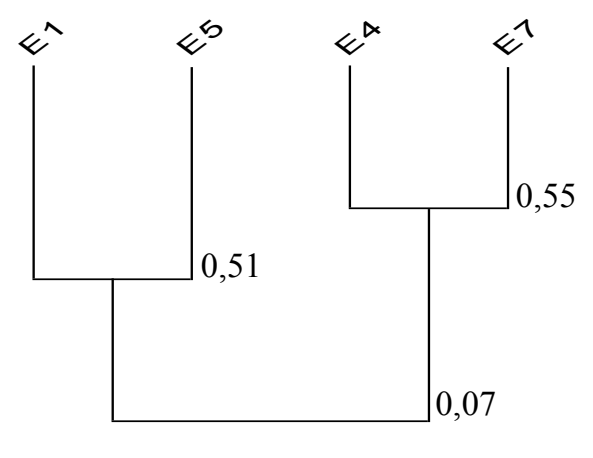

$\mathrm{B}_{1}$

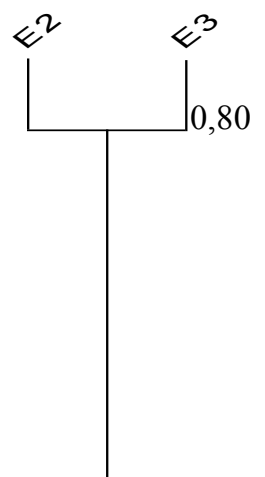

$\mathrm{B}_{2}$

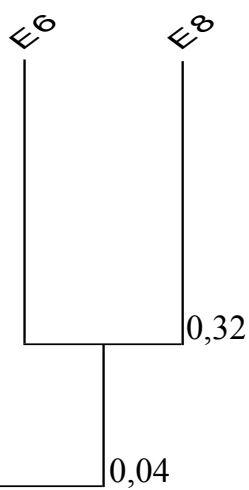

Figura 04 - Árvore de similaridade das respostas dos entrevistados.

Na primeira análise buscou-se avaliar, independente de sexo, idade ou bairro de moradia, apenas os aspectos que formaram a imagem de residência da população entrevistada. Uma visão geral da árvore possibilitou distinguirmos, na hierarquia, da esquerda para direita, duas grandes classes de variáveis: classe $A$ subdividida em $A_{1}$ e $A_{2}$, e classe $B$, subdividida em $B_{1}$ e $B_{2}$.

A classe A corresponde a um conjunto de aspectos associados a uma moradia em lugar que ofereça qualidade de vida, no sentido de um ambiente saudável, aos seus moradores. A classe B envolve aspectos de localização e segurança da moradia, porém, mais associados à residência como investimento do que expressando, como proposto por Bachelard (1993), o "espaço de nossa felicidade". Estes argumentos, de localização e investimento, estiveram presentes em muitas das entrevistas em todos os bairros, provavelmente associados ao implemento imobiliário experimentado pela cidade nos últimos anos, provocado, entre outros fatores, pelo estabelecimento da cidade como sede da Copa do Mundo FIFA em 2014.

No primeiro nível, na classe $B$, a subclasse $B_{1}$ mostra justamente a similaridade de 0,80 , a correlação mais forte de todos os pares de atributos, entre as respostas dos indivíduos que associaram a residência ideal aos aspectos perceptivos "Boa Localização", eixo $E_{2}$, e "Bom Investimento", eixo $E_{3}$. Muitas das referências ao eixo $E_{2}$ foram associadas às proximidades da UFMT e do Shopping Três Américas, 
associações justificadas de modo geral, como proposto anteriormente, pela recente supervalorização dos imóveis urbanos na cidade.

Ainda na classe $B$, na subclasse $B_{2}$ aparece uma relação entre as variáveis "Empresarial e Comercial", eixo $E_{6}$, e "Vizinhança Agradável", eixo $E_{8}$, com a menor similaridade, de 0,32, entre os pares. Esta subclasse também está associada a um conjunto de moradores que consideraram comercialmente favorável o estabelecimento de moradia nas proximidades de uma área com forte vocação comercial e empresarial. Com relação ao eixo $\mathrm{E}_{8}$, as referências citadas como vizinhança agradável, além do aspecto da existência de bons vizinhos e boas relações interpessoais, fizeram-se mais evidentes as questões de segurança, no sentido que imóveis em regiões de elevada insegurança tem seus valores depreciados ao longo dos anos.

$\mathrm{Na}$ classe $\mathrm{A}$, a subclasse $A_{2}$ apresenta uma similaridade, de 0,55 , entre as variáveis "Clima Agradável", eixo $E_{4}$, e "Único e Especial", eixo $E_{7}$. Em virtude do clima da cidade, reconhecidamente quente, o lançamento recente de empreendimentos imobiliários muito arborizados, com espaços de meditação e caminhada entre as árvores, em geral, distantes do perímetro central da cidade, pode explicar o imaginário de moradia por parte dos entrevistados como único e especial uma moradia que reúna estas características. Para Lenzholzer e Koh (2010) as pessoas possuem imagens ou esquemas mentais de microclimas urbanos que se relacionam com a disposição espacial do lugar, de forma que as representações das configurações espaciais destes ambientes "especiais" são relacionadas pelos indivíduos com as propriedades mais prováveis dos correspondentes microclimas.

Os aspectos "Animado e Dinâmico", eixo $E_{1}$, e "Elegante e Moderno", eixo $E_{5}$, correlacionados com menor similaridade, foram relacionados por moradores que associaram percepções aprazíveis a um imóvel com toda qualidade disponível no mercado, de preferência novo. Esses entrevistados consideraram importantes em um lugar os equipamentos públicos, com atrativos diversos, como a rotatividade de um shopping center em contínuo movimento.

Para homens o aspecto mais importante foi a presença de empresas e comércios, enquanto que para as mulheres, com menor similaridade, a vizinhança agradável foi o atributo mais importante. $\mathrm{Na}$ análise por faixa etária, os jovens 
associaram a imagem ideal de residência ao clima agradável, enquanto que os adultos relacionaram a dinâmica do bairro e a presença de equipamentos públicos. Para a faixa etária mais elevada todos os atributos são neutros, como se estivessem divididas entre todas as relações implicativas, compatíveis com o padrão de respostas observado nesta análise.

$\mathrm{Na}$ correlação por bairros, as diferenças existentes entre os perfis de moradores, resultaram em diferentes aspectos relacionados como mais importantes. A correlação mais forte foi identificada entre os moradores do Jardim das Américas e a questão da localização, eixo $E_{2}$, talvez por julgarem a característica como a mais importante da atual moradia.

Para os moradores do Santa Cruz a vizinhança agradável foi o atributo mais importante para a escolha da moradia, enquanto que os moradores do Conjunto Habitacional Maria de Lourdes, habituados às elevadas temperaturas do período vespertino e o arrefecimento noturno produzido pela área verde próxima, associaram o imaginário de moradia ideal a um lugar com um clima agradável. Com um nível de similaridade muito baixo os moradores do Jardim Itália associaram ao atributo "Empresarial e Comercial", e os moradores do Renascer ao atributo "Moderno e Elegante", uma imagem de residência em total contraposição a atual condição de moradia destes últimos, porém mostra a projeção destes com as propostas apresentadas pelos empreendimentos imobiliários.

Questionados sobre a satisfação com a atual residência, os moradores do Renascer, bairro carente de infraestrutura, equipamentos públicos, lazer, segurança e áreas verdes, mostraram-se mais descontentes com a atual moradia, seguidos pelos moradores do Jardim Itália, vizinho do Renascer, com melhores condições estruturais, porém também abandonado pelos serviços públicos. Nos demais bairros a satisfação com a atual moradia foi quase uma unanimidade entre os entrevistados. Nas justificativas dos moradores do Santa Cruz foram muito comuns referências às áreas verdes do bairro como: "lugar maravilhoso de se morar", "essencial manter o lugar bem arborizado", "bastante árvores" ou "bem mais fresco".

Ainda em relação às impressões a respeito dos seus bairros, os moradores do Santa Cruz, do Conjunto Habitacional Maria de Lourdes e do Jardim Itália 
consideraram os seus bairros com temperaturas mais amenas que os demais lugares da cidade, por outro lado os moradores do Renascer e do Jardim das Américas reconheceram os seus bairros como lugares de temperaturas elevadas. Os resultados da análise microclimática mostrou que os bairros Renascer e Jardim das Américas apresentaram ambientes térmicos muito parecidos. A proximidade, além de apresentarem estruturas espaciais quantitativamente semelhantes pode explicar este comportamento. No Conjunto Habitacional Maria de Lourdes, marcado pela contradição, no lugar foi registrada a maior temperatura do estudo, de $42,4{ }^{\circ} \mathrm{C}$, no período vespertino da estação seca, no entanto, no período noturno das duas estações, o padrão de construções térreas sofre o efeito de arrefecimento do ar produzido pela forte influência da mata que abraça o bairro. Recém-construído, contrapondo a todos os estudos voltados ao clima urbano, o bairro apresenta estruturas espaciais caracterizadas pelas elevadas densidade de construções e impermeabilização dos solos, reduzidas arborização pública e áreas verdes, além da inexistência de quintais nas residências.

As impressões dos moradores corresponderam em parte aos resultados dos ambientes térmicos de cada bairro apresentados nos itens anteriores. Esta constatação sugere que, atualmente, essa percepção climática a partir das configurações espaciais de um ambiente pode ser um dos fatores determinantes para a escolha do local de moradia por um indivíduo.

Os moradores do Santa Cruz e do Jardim das Américas consideraram os seus bairros arborizados e, a maior parte deles, disseram manter árvores a frente de suas residências. Moradores do Jardim Itália, Renascer e do Conjunto Habitacional Maria de Lourdes, na sua maioria, responderam de forma negativamente estas questões. No Conjunto Habitacional Maria de Lourdes, mesmo reconhecendo a mata que envolve o bairro como muito importante para a amenização climática do bairro, não consideraram como parte deste, uma vez que se encontra em áreas particulares. Neste bairro a arborização urbana considerou apenas espécies da região, sem considerar aspectos de copa e desciduidade, de forma que muitas destas árvores foram retiradas com o argumento de danificarem as calçadas ou por um sombreamento ineficiente. 
Quesitos julgados como importantes para o bem-estar no espaço são fortes características do sentimento topofilico para com o lugar. Dentro desta definição, na comparação entre os bairros, os moradores do Santa Cruz apresentaram maiores laços afetivos com o lugar em que residem, baseados em parte pelo papel, psicológico e climático, desempenhado pela vegetação ainda exuberante do bairro.

\section{CONCLUSÃO}

A característica de clima ameno, comparativamente aos demais bairros do estudo, além das outras funções da vegetação no ambiente urbano, justificaram os maiores laços afetivos encontrados entre os moradores do Santa Cruz e o lugar em que residem. Porém, infelizmente, a imagem de moradia da maior parte dos entrevistados esteve maior fortemente associada aos atributos "bom investimento" e "boa localização", ficando em segundo plano as melhores condições ambientais do lugar de morada.

Construída ao longo da história de vida da pessoa, a imagem de residência de um indivíduo vem da sua interação com o lugar que vive. Assim, talvez a nossa história recente não traga boas lembranças dos nossos espaços modernosos, públicos ou privados, muitas vezes locados em situações improvisadas, ambientalmente inadequadas, que nem sequer lembram aquelas construções de outrora, adaptadas ao clima local, estas sim, são a própria extinção.

O crescimento urbano acentuado das cidades médias trouxe um problema novo para a sua população, a maior dificuldade na mobilidade urbana, processo que reflete na degradação da qualidade de vida, além do valor do imóvel, pago ao longo da vida do cidadão, que também não pode ser subestimado nesta análise. A especulação imobiliária, o valor do aluguel, a dificuldade dos transportes podem justificar a percepção de moradia como investimento.

Dessa maneira, em meio a tantas necessidades, a menor importância dada ao saneamento básico, a conservação de praças e áreas verdes, a proteção dos calores e frios do lugar, pode também ter relação com o fato de não conhecermos o tempo em que a água era abundante em quantidade e qualidade e as residências, além de 
patrimônio da família, eram, graças aos quintais arborizados e a uma arquitetura voltada para o clima, um refúgio contra o calor das tardes quentes.

\section{REFERÊNCIAS BIBLIOGRÁFICAS}

ABRIC, J. C. Pratiques Sociales et Représentations. Presses Universitaires de France: Paris, FRA, 1994. 253p.

ADDISON, E. E. A Percepção Ambiental da População do Município de Florianópolis em Relação à Cidade. 2003. Dissertação (Mestrado em Engenharia de Produção) Centro Tecnológico, Universidade Federal de Santa Catarina. $151 \mathrm{f}$. Florianópolis, SC.

BACHELARD, G. A Poética do Espaço. 2. ed. Martins Fontes: São Paulo, 1993. 242p.

BARROS, M. P.; MUSIS, C. R.; HORNICK, C. Parque da Cidade Mãe Bonifácia, Cuiabá-MT: topofilia e amenização climática em um fragmento de cerrado urbano. REVSBAU, v.5, n.2, p.01-18. Jun. 2010a.

CAMPELO JÚNIOR, J. H.; CASEIRO, F. T.; PRIANTE FILHO, N.; BELLO, G. C. C.; MAITELLI, G. T.; ZAMPARONI, C. A. G. P. Caracterização Macroclimática de Cuiabá. In: ENCONTRO NACIONAL DE ESTUDOS SOBRE O MEIO AMBIENTE, 3, 1991. Londrina. Anais. Londrina, PR: FUEL, 1991. p.545-552.

DE MUSIS, C. R.; CARVALHO, S. P.; NIENOW, N. S. Avaliação da Saturação de Questões Abertas Utilizando Simulação Monte Carlo. Revista de Educação Pública. v.18, n.38, p.505-516. Set. 2009.

GALDINO, Y. S. N.; ANDRADE. L. M. S. Interações entre a Cidade e Paisagem ao longo da Sub-Bacia do Barbado, Cuiabá - MT. ENCONTRO NACIONAL DA ANPPAS, 4, 2008, Brasília. Anais. Brasília: Anppas, 2008. p.1-19.

GOOGLE EARTH. Aplicativo de Imagens de Satélites. Disponível em: <http://www.google.com.br/intl/pt-BR/earth/>. Acesso em 04 fev. 2010.

GUARIM, V. L. M. S.; VILANOVA, S. R. F. Parques Urbanos de Cuiabá, Mato Grosso: Mãe Bonifácia e Massairo Okamura. Entrelinhas-EdUFMT: Cuiabá, 2008. p.112. 
HIGA, T. C. S. Processo de Ocupação e Formação Territorial. In: Morene G.; Higa T. C. S. organizadores. Geografia de Mato Grosso: território, sociedade e ambiente. Entrelinhas: Cuiabá, 2005. 296p.

INSTITUTO BRASILEIRO DE GEOGRAFIA E ESTATÍSTICA - IBGE. Primeiros Resultados do Censo 2010, 2010. Disponível em: <http://www.censo2010.ibge.gov.br>. Acesso em 14 dez. 2010.

INSTITUTO NACIONAL DE PESQUISAS ESPACIAIS - INPE. Base de dados CBERS e Landsat, 2009a. Disponível em: <http://www.dgi.inpe.br/>. Acesso em 12 jul. 2009.

KAISER, I. M.; FARIA, J. R. G. Validation of Transects For Air Temperature and Moisture Profiles Measurements in Urban Areas Under High Diurnal Air Temperatures Variation. In: INTERNATIONAL CONFERENCE ON PASSIVE AND LOW ENERGY ARCHITECTURE, 18, 2001, Florianópolis. Anais. Florianópolis, SC: PLEA/ANTAC/UFSC, 2001, p.571-575.

LENZHOLZER, S.; KOH, J. Immersed in Microclimatic Space: microclimate experience and perception of spatial configurations in Dutch squares. Landscape and Urban Planning, v.95, n.1-2, p.1-15. Mar. 2010.

LLINARESA, C.; PAGEB, A. F. Differential Semantics as a Kansei Engineering Tool for Analysing the Emotional Impressions Which Determine the Choice of Neighbourhood: the case of Valencia, Spain. Landscape and Urban Planning, v.87, n.4, p.247-257. Set. 2008.

MAAS, J.; VERHEIJ, R. A.; GROENEWEGEN, P. P.; de VRIES, S.; SPREEUWENBERG, P. Green Space, Urbanity, and Health: how strong is the relation? Journal of Epidemiology and Community Health. v.60, n.7, p.587-592. Jul. 2006.

MAITELLI, G. T. Interações Atmosfera-Superfície. In: Morene G.; Higa T. C. S. organizadores. Geografia de Mato Grosso: território, sociedade e ambiente. Entrelinhas: Cuiabá, 2005. 296p.

MENDONÇA, F. Clima e Planejamento Urbano em Londrina. In: Monteiro C. A. F.; Mendonça F. organizadores. Clima Urbano. Contexto: São Paulo, 2003. 192p.

MONTEIRO, C. A. F. Teoria e Clima Urbano. In: Monteiro C. A. F.; Mendonça F. organizadores. Clima Urbano. Contexto: São Paulo, 2003. 192p.

PEZZUTO, C. C. Avaliação do Ambiente Térmico nos Espaços Urbanos Abertos. Estudo de caso em Campinas, SP. 2007. Tese (Doutorado em Engenharia Civil) 
Faculdade de Engenharia Civil, Arquitetura e Urbanismo, Universidade Estadual de Campinas. 197f. Campinas, SP.

PIAIA, I. I. Geografia de Mato Grosso. 3. ed. EDUNIC: Cuiabá, 1997. 184p.

SIQUEIRA, E. M. História de Mato Grosso: da ancestralidade aos dias atuais. Entrelinhas: Cuiabá, 2002. 272p.

TUAN, Y F. Topofilia: um estudo da percepção, atitudes e valores do meio ambiente. Difel: São Paulo, 1980. 288p.

VILARINHO NETO, C. S. Dinâmica Urbana Regional. In: Morene G.; Higa T. C. S. organizadores. Geografia de Mato Grosso: território, sociedade e ambiente. Entrelinhas: Cuiabá, 2005. 296p. 